\title{
Primary Care Management of Asthma Exacerbations or Attacks: Impact of the COVID-19 Pandemic
}

\author{
Monica Fletcher (D) - Thys van der Molen • Warren Lenney • \\ Isabelle Boucot · Bhumika Aggarwal · Emilio Pizzichini
}

Received: November 22, 2021 / Accepted: January 21, 2022 / Published online: February 14, 2022

(C) The Author(s) 2022

\section{ABSTRACT}

The COVID-19 pandemic has brought a renewed focus on appropriate management of chronic respiratory conditions with a heightened awareness of respiratory symptoms and the requirement for differential diagnosis between an asthma attack and COVID-19 infection. Despite early concerns in the pandemic, most studies suggest that well-managed asthma is not a risk factor for more severe

Supplementary Information The online version contains supplementary material available at https:// doi.org/10.1007/s12325-022-02056-x.

M. Fletcher (訩

The Usher Institute, University of Edinburgh, Edinburgh, UK

e-mail: Monica.Fletcher@ed.ac.uk

T. van der Molen

Department of General Practice and GRIAG

Research Institute, University Medical Center

Groningen, University of Groningen, Groningen,

The Netherlands

W. Lenney

Department of Pharmacy and Bioengineering,

University of Keele, Keele, Staffordshire, UK

I. Boucot · E. Pizzichini

Respiratory, GlaxoSmithKline, Brentford, London, UK

B. Aggarwal

Respiratory, General Medicines Emerging Markets, GlaxoSmithKline, Singapore 139234, Singapore
COVID-related outcomes, and that asthma may even have a protective effect. Advice on the treatment of asthma and asthma attacks has remained unchanged. This article describes some challenges faced in primary care asthma management in adults and in teenagers, particularly their relevance during a pandemic, and provides practical advice on asthma attack recognition, classification, treatment and continuity of care. Acute attacks, characterised by increased symptoms and reduced lung function, are often referred to as exacerbations of asthma by doctors and nurses but are usually described by patients as asthma attacks. They carry a significant and underestimated morbidity and mortality burden. Many patients experiencing an asthma attack are assessed in primary care for treatment and continuing management. This may require remote assessment by telephone and home monitoring devices, where available, during a pandemic. Differentiation between an asthma attack and a COVID-19 infection requires a structured clinical assessment, taking account of previous medical and family history. Early separation into mild, moderate, severe or life-threatening attacks is helpful for continuing good management. Most attacks can be managed in primary care but when severe or unresponsive to initial treatment, the patient should be appropriately managed until transfer to an acute care facility can be arranged. Good quality care is important to prevent further attacks and must include a follow-up appointment in 
primary care, proactive regular dosing with daily controller therapy and an understanding of a patient's beliefs and perceptions about asthma to maximise future self-management.

Keywords: Asthma; Attacks; Exacerbations; Management; Pandemic; Primary care

\section{Key Summary Points}

During pandemics caused by respiratory viruses, such as in COVID-19, it is even more important, where possible, to prevent asthma attacks and to intervene and manage appropriately when they occur.

The advice on managing attacks remains unchanged.

Asthma attacks represent an increase in patients' symptoms and a reduction in lung function which may lead to an increased use of reliever medication, highlighting a need for inhaler technique assessment, a treatment compliance check and appropriate asthma treatment together with a written asthma action plan.

Most asthma attacks are mild or moderate and can be managed entirely in primary care, but this depends on prompt recognition and classification of attack severity, whether face to face or remotely.

Whether an asthma attack is managed in primary care or in an acute care setting, every patient should be prescribed regular asthma controller therapy and have a follow-up visit in primary care soon after, certainly within 2 weeks, to assess response and to establish regular maintenance treatment to prevent further problems with asthma.

\section{INTRODUCTION}

At the outset of the COVID-19 pandemic, there were concerns about its impact on patients with asthma and other chronic respiratory conditions [1], both in terms of its effect in triggering acute exacerbations or attacks, and as a risk factor for more severe disease and death [2]. As the pandemic continued, several studies showed a reduction in asthma attacks reported in primary care and in emergency departments [3-7], possibly related to social distancing, the wearing of face masks, less air pollution, and improved self-management $[5,8,9]$, rather than pandemic-related healthcare avoidance [7]. In addition, reports from many countries have suggested that well-managed asthma is not a risk factor for more severe outcomes $[2,10]$, and that asthma may offer some protection against the detrimental effects of COVID-19 infection [2, 11]. Throughout the pandemic, asthma management guidelines have reinforced the importance of continuing treatment to maintain asthma control and reduce the risk of future attacks [12-14]. The advice on managing asthma attacks remains unchanged.

Asthma attacks are acute asthma episodes that comprise an increase in symptoms and a reduction in lung function needing increased reliever medication use, and perhaps a change in controller treatment [15]. They are also referred to as asthma exacerbations or flare-ups; however, a 2018 Lancet commission called for the term asthma attack to replace these terms in recognition of their importance as markers of a high risk of future attacks and even death, rather than mild episodes of inconvenience [16]. The term attack is also preferred by patients as it describes how they feel and is better understood by their friends and family [17]. For these reasons, we use the term attack in this article.

Asthma attacks are a major health burden to patients and a financial and staff burden to public health services [15]. They usually occur in those with an existing diagnosis of asthma but may be the first signs a patient seeks healthcare support [15]. Although greater 
asthma severity is associated with more attacks [18], all with asthma, irrespective of its severity, are at risk [18-21]. An asthma attack is a significant predictor of future events [18, 22-24]. The severe attack rate (i.e. those requiring treatment with oral corticosteroids (OCS), an emergency department visit or hospitalisation) has been reported in epidemiological surveys as $0.1-0.2$ per patient per year, with most treated with OCS only $[18,25]$. Although it is uncommon that patients with asthma have asthmarelated hospitalisations or die (less than 1\%) [26], prompt diagnosis of an attack with determination of its severity is important, as delay can be fatal [27].

In most countries, primary care is the first place of contact $[28,29]$. Primary care physicians (PCPs) deal with many other asthma challenges, including access to asthma medicines, spacer device availability, patient adherence to treatment regimens, implementation of a written asthma action plan, difficult access to care in rural areas and the demand of patients' everyday work and life [29-32]. Many asthmarelated deaths can be prevented by better education, use of asthma action plans, more accurate and timely diagnosis, rapid referral to a respiratory specialist when needed, better follow-up, and encouragement to continue taking regular preventative medicines [33, 34]. PCPs have faced additional challenges in the COVID19 pandemic, not only in the differential diagnosis between asthma attacks and COVID-19 infections but also in assessing the severity of an attack and asthma control via remote consultation to ensure the appropriate acute treatment and future care [35].

This article describes the challenges faced in primary care in managing asthma attacks in adults and teenagers, their relevance during a pandemic and offers practical advice about attack recognition, classification, treatment and continuing care (Fig. 1).

This article is based on previously conducted studies and does not contain new clinical studies involving human participants or animal studies by any of the authors.

\section{WHAT ARE THE KEY INDICATORS FOR RECOGNISING AN ASTHMA ATTACK AND WHAT IS THE DIFFERENCE BETWEEN AN ASTHMA ATTACK AND A COVID-19 INFECTION?}

Acute asthma attacks are characterised by a progressive increase in symptoms of breathlessness, cough, wheezing and/or chest tightness, plus a fall in lung function [15]. For differentiation between an attack and a COVID19 infection, a structured clinical assessment is recommended, involving a detailed history and review of the patient's clinical records including review of any investigations such as recent peak expiratory flow rate (PEFR), spirometry or blood eosinophil findings $[35,36]$. Whilst both may present with cough and breathlessness, patients experiencing an attack usually present with wheeze, a reduced PEFR and demonstrate symptoms which improve following use of a reliever inhaler $[12,13,35]$. A personal or family history of asthma is another criterion for a higher probability of asthma [36]. COVID-19 infection is more likely to be signalled by a high body temperature, a dry hacking continual cough, flu-like symptoms (fatigue, headache), loss of taste/smell, and symptoms unresponsive to the use of reliever treatment $[12,13,35]$. In many, differential diagnosis may be possible without PEFR and spirometry, which is preferable because of the potential transmission of viral infections [36]. As new variants of COVID19 emerge, differences may become less distinct.

It is helpful to bear in mind that the most common trigger of an asthma attack is a viral respiratory infection or allergen exposure, both of which are subject to seasonal variation $[15,37,38]$. Pollutants (tobacco smoke, outdoor and indoor air pollutants) may also trigger an attack. Attacks are heterogeneous in their time course and severity, making them challenging to recognise and treat in primary care [39]. Several studies have shown variations in reliever use before and during the time course of an asthma attack [40-42], and such patterns can 
1) Assess

$\checkmark$ Physical exam: Use of accessory muscles? Cyanosis? Ability to talk in sentences? Chest retractions? Agitation?

$\checkmark$ Medical history: previous acute exacerbations, allergies, past adherence, current therapy, hospitalisations.

$\checkmark$ Investigations/observations: Pulse oximetry $\left(\mathrm{SaO}_{2}\right)$, pulse $(\mathrm{bpm})$, respiratory rate (breaths/min), peak expiratory flow.

$\checkmark$ Other considerations: social situation, psychological problems, lives alone.

2) Classify

Mild/moderate Normal speech/talks in phrases, increased respiratory rate, $\mathrm{SaO}_{2}$ on air $\geq 90 \%, \leq 120 \mathrm{bpm}$

Severe Breathlessness interferes with speech, use of accessory muscles, $\geq 30$ breaths $/ \mathrm{min}$,

$\mathrm{SaO}_{2}$ on air $<90 \%,>120$ bpm

Life-threatening Prevents speech, central cyanosis, exhaustion, silent chest, pallor, poor respiratory effort, sweating

use of accessory muscles

3) Treat

SABA Salbutamol ( $100 \mu \mathrm{g} /$ actuation): $4-10$ puffs via pMDI + spacer every 20 mins for 1 hour

OCS Prednisolone 40-50mg daily

Severe, life-threatening or inadequate response: urgent transfer to an acute care facility

Whilst waiting: Salbutamol, controlled oxygen therapy (aim $\mathrm{SaO}_{2} 93-95 \%$, maximum 98\%)

4) Continuity of care (follow-up visit and prevention)

a) Follow-up

b) Prevention
Follow-up appointment within 2-7 days.

$\checkmark$ Check correct inhaler technique at every review

$\checkmark$ Check adherence

$\checkmark$ Identify/address modifiable risk factors (eg. Smoking, allergens, anxiety, obesity)

$\checkmark$ Consider increase in controller therapy: step-up ICS/LABA dose, consider add-on therapy if severe uncontrolled asthma

$\checkmark$ Asthma action plan: clear, explicit instruction on how to recognize symptoms and what to do

$\checkmark$ Patient education
Fig. 1 Overview of the management of acute attacks of asthma in primary care. $b p m$ beats per minute, ICS inhaled corticosteroid, $L A B A$ long-acting $\beta_{2}$-agonist, $O C S$ oral

serve as a helpful indicator of an impending attack and its subsequent control.

\section{WHAT ARE THE CLINICAL SIGNS AND SYMPTOMS FOR CLASSIFYING THE SEVERITY OF AN ASTHMA ATTACK DURING A PANDEMIC?}

Appropriate management depends on the asthma attack severity so it is important to immediately assess how severe it really is (Table 1) $[15,27,43,44]$ and where best to manage it (Fig. 2). corticosteroid, $p M D I$ pressurised metered-dose inhaler, $\mathrm{SaO}_{2}$ saturated oxygen, $\mathrm{SABA}$ short-acting $\beta_{2}$-agonist

Under conditions of normal clinical practice, a full clinical history and a careful physical examination are required to assess heart rate, the use of accessory muscles, any chest wall retraction, wheezing, level of breathlessness, respiratory rate, cyanosis of lips and tongue, any agitation or reduced consciousness. Also measurement of lung function (PEFR or forced expiratory volume in $\left.1 \mathrm{~s}\left(\mathrm{FEV}_{1}\right)\right)$ are helpful to define an attack as mild, moderate, severe, or life-threatening (Table 1) [15, 27, 43, 44]. Objective measures of lung function are more reliable indicators of attack severity than symptoms [15, 44]. Pulse oximetry, if available, 
Table 1 Asthma attack severity classification in adults and young people ( $\geq 12$ years of age) $[15,27,43,44]$

\begin{tabular}{|c|c|c|c|c|}
\hline \multirow{3}{*}{ Clinical signs/ symptoms } & \multicolumn{4}{|c|}{ Severity of attack } \\
\hline & & & & \\
\hline & Mild & Moderate & Severe & Life-threatening \\
\hline Breathlessness & On activity/exertional & $\begin{array}{l}\text { Interferes with or limits normal } \\
\text { activity }\end{array}$ & $\begin{array}{l}\text { At rest or interferes } \\
\text { with speech }\end{array}$ & Prevents speech \\
\hline Speech & Normal speech & Speech in phrases & Unable to complete sentences & Unable to speak \\
\hline $\begin{array}{l}\text { Extrapulmonary } \\
\text { symptoms/Alertness }\end{array}$ & Usually not agitated & Maybe agitated & $\begin{array}{l}\text { Possible cyanosis of the lips } \\
\text { Agitation, nasal flaring, sweating }\end{array}$ & $\begin{array}{l}\text { Central cyanosis } \\
\text { Drowsy, exhaustion, pallor, } \\
\text { sweating }\end{array}$ \\
\hline $\begin{array}{l}\text { Suprasternal restrictions; } \\
\text { use of accessory muscles }\end{array}$ & $\begin{array}{l}\text { Usually no suprasternal } \\
\text { retractions or use of accessory } \\
\text { muscles }\end{array}$ & $\begin{array}{l}\text { Commonly suprasternal } \\
\text { retractions, possible use of } \\
\text { accessory muscles }\end{array}$ & $\begin{array}{l}\text { Usually suprasternal retractions } \\
\text { and use of accessory muscles }\end{array}$ & $\begin{array}{l}\text { Paradoxical thoraco-abdominal } \\
\text { movement, use of accessory } \\
\text { muscles }\end{array}$ \\
\hline Respiratory rate & Increased & Increased & $\geq 30 / \mathrm{min}$ & $\begin{array}{l}\text { Poor respiratory effort/silent } \\
\text { chest }\end{array}$ \\
\hline Heart rate (bpm) & $<110$ & $110-120$ & $>120$ & Arrhythmia \\
\hline Oxygen saturation (on air) & $\geq 90 \%$ & $\geq 90 \%$ & $<90 \%$ & $<90 \%$ \\
\hline $\begin{array}{l}\text { PEF (percentage of } \\
\text { predicted) }\end{array}$ & $\geq 50 \%$ & $\geq 40-50 \%$ & $<40-50 \%$ & $<33 \%$ \\
\hline
\end{tabular}

bpm beats per minute, $P E F$ peak expiratory flow, $\mathrm{SaO}_{2}$ oxygen saturation, $y$ years

is also helpful to determine severity and has prognostic value [15].

During the COVID-19 pandemic the recommendations in Table 1 and Fig. 2 are suggested using a combination of patient self-assessment tools such as PEFR monitoring where available, an asthma action plan and ehealth strategies personalised for patients with asthma. This means leveraging the use of home monitoring devices assessing heart rate, breathing rate and oxygen saturation, handheld spirometers, and smart devices assessing adherence, and inhalation technique $[35,36,45,46]$.

Remote clinical assessment, so often required during the COVID-19 pandemic, relies on a telephone call consultation, preferably augmented by a video link [35]. Some patients may still require face-to-face consultation. Patients' key signs and symptoms should be determined in the context of their wider clinical history and through questioning them about their symptoms in relation to their normal health status such as their usual breathlessness and respiratory rate $[35,36,47]$. Try to establish any risk factors for asthma-related death (a history of near-fatal asthma, excessive use of reliever treatment (more than one cannister per month), not using or poor adherence to inhaled corticosteroid (ICS) preventative treatment, recent or current use of OCS, a recent emergency hospital visit or admission with asthma, a history of psychiatric disease or psychosocial problems, food allergy, comorbidities, including obesity and cardiovascular disease $[15,27,44])$. Patient medical records should also be checked for risk factors of poor outcome with COVID-19 infection. Patients who struggle to complete sentences, have a respiratory rate of 25 breaths/min or higher, a PEFR less than 50\% of predicted or a heart rate of $120 \mathrm{bpm}$ or higher, all suggest a severe attack, needing prompt transfer to an acute care facility (Table 1; Fig. 2) [15, 27, 43, 44].

Self-assessment by patients to monitor their asthma using both objective and subjective measures is a pragmatic approach. The assessment of asthma control at home using asthma control questionnaires (e.g. Asthma Control Test or Asthma Control Questionnaire) provides one tool of assessment $[35,36]$. Remote monitoring through patients recording their daily PEFR readings, if available, and/or the presence of any asthma symptoms in a daily diary, may also help observe a cause-and-effect relationship 


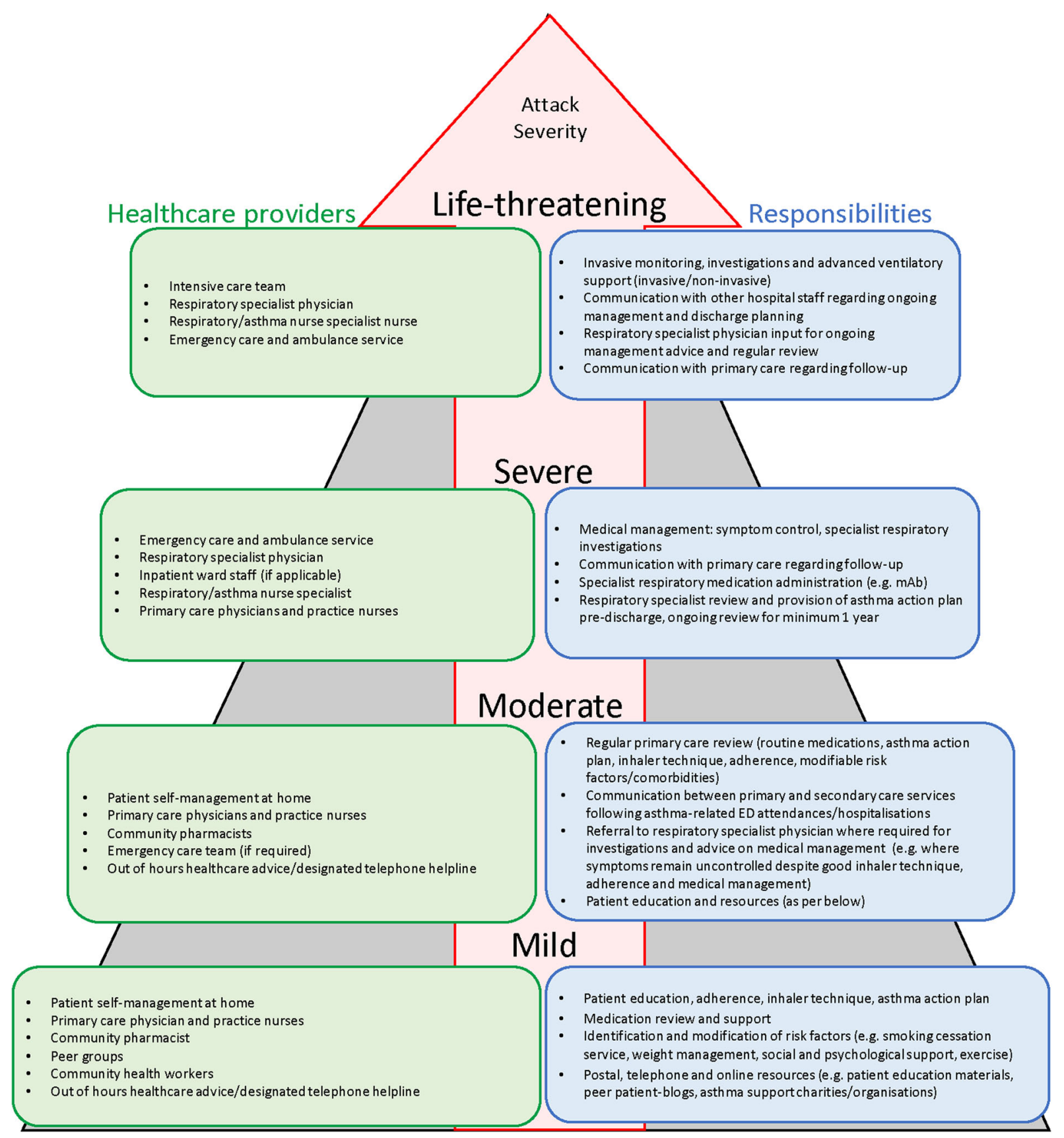

Fig. 2 Stepwise healthcare provider model for acute attacks $[15,27,94]$. ED emergency department, $m A b$ monoclonal antibody

between exposure to triggers and decrements in peak flow and/or exacerbations of asthma and to give early warning signs of a potential deterioration, for both PCPs and patients via their written action plan (Fig. S1, Supplementary Material). However, patients may be reluctant to continue this for a substantial length of time. 


\section{HOW CAN ASTHMA ATTACKS BE MANAGED EFFECTIVELY IN PRIMARY CARE DURING A PANDEMIC?}

The advice on managing asthma remains unchanged during the COVID-19 pandemic $[12,13,48]$. A shortage of asthma inhalers was observed during the pandemic; the shortage of short-acting $\beta_{2}$-agonist (SABA) inhalers reinforced the importance and well-established role of SABA in the current management of asthma [49]. For most patients with asthma, the risk of inadequately treating an asthma attack is worse than the risk from COVID-19 infection [12].

Most attacks are classified as mild or moderate and can be entirely managed in primary care. Severe or life-threatening attacks usually require treatment in an acute care facility
(Fig. 3) [15]. A comparative overview of treatment recommendations in primary care versus acute care is shown in Table S1 (Supplementary Material). There are some differences in recommendations across guidelines.

\section{Mild and Moderate Asthma Attacks}

All patients need immediate treatment with inhaled SABA, usually salbutamol/albuterol, together with the prompt introduction of orally administered prednisolone [15, 27, 43, 44]. Hypoxaemia requires supplemental oxygen. Patients should be closely observed and treatment adjusted according to response.

Inhaled SABAs have a rapid onset of action (less than $5 \mathrm{~min}$ ), are well tolerated, and repeated administration achieves incremental bronchodilatation [43]. In adults and young

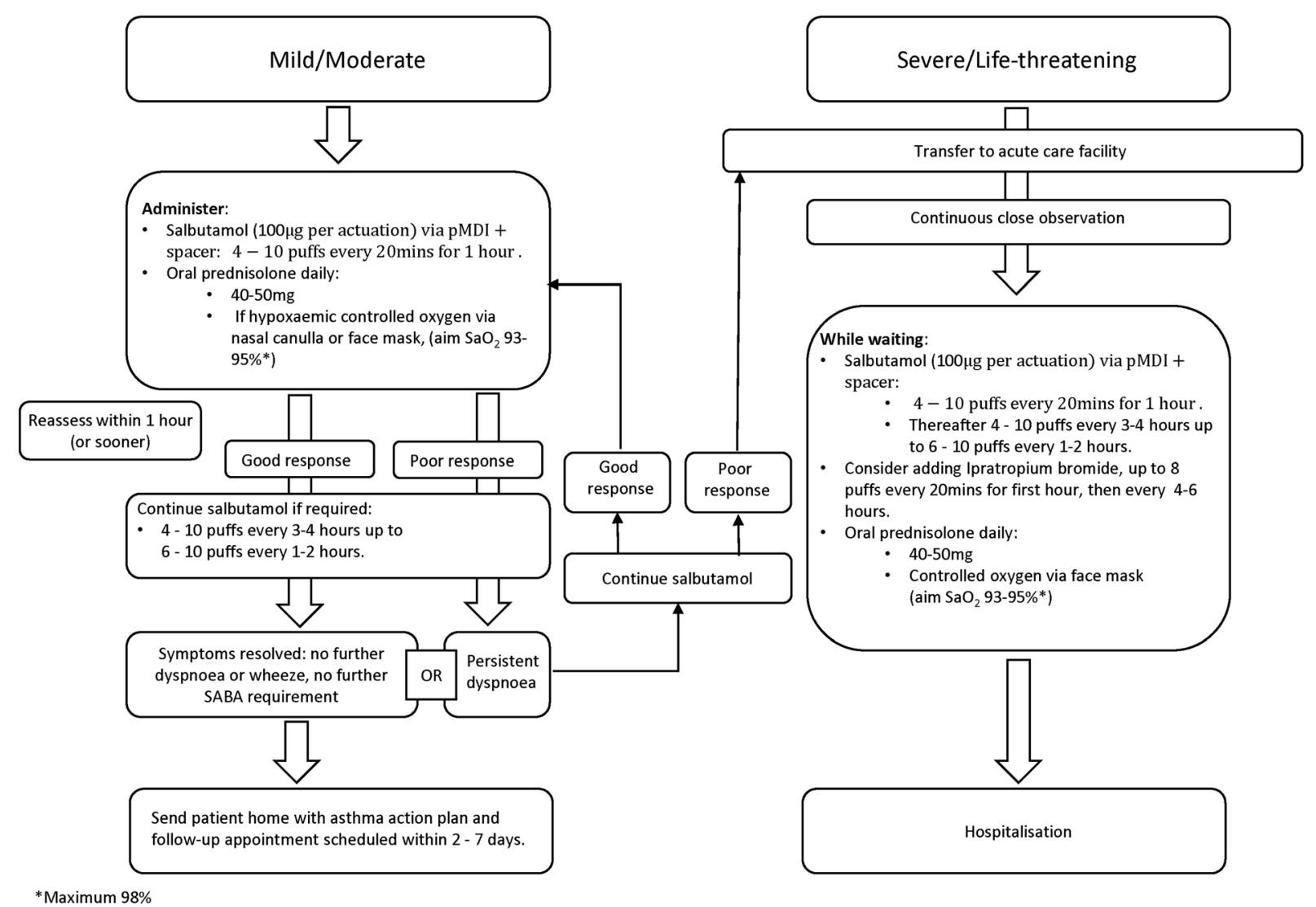

Fig. 3 Treatment of acute attacks of asthma in adults/young people ( $>12$ years of age). $p M D I$ pressurised metered-dose inhaler, $\mathrm{SABA}$ short-acting $\beta_{2}$-agonist, $\mathrm{SaO}_{2}$ saturated oxygen 
people, the recommended dose is $4-10$ puffs of inhaled SABA via a pressurised metered-dose inhaler (pMDI) plus a spacer (preferably a larger volume spacer, $750 \mathrm{~mL}$ ) every $20 \mathrm{~min}$ for $1 \mathrm{~h}$ [15]. If symptoms rapidly resolve, no further SABA treatment may be needed; consider sending the patient home with appropriate controller therapy, an asthma management plan and a follow-up appointment [15]. Doubling the dose of ICS has been shown to improve asthma outcomes in self-management studies [50], although this strategy is not well supported by results of placebo-controlled trials $[15,51,52]$. It is hypothesised that in real life, patients may at this point be reintroducing the inhaled steroids as originally prescribed rather than actually doubling their medicationhence the incongruence.

OCS treat the underlying inflammation but take up to $4 \mathrm{~h}$ to show clinical benefit; therefore, they should be commenced as soon as possible (i.e. at the same time as initial SABA treatment). A dose of orally administered prednisolone $40-50 \mathrm{mg}$ once daily is an accepted dose for teenagers and adults for 5-7 days $[15,27]$. To prevent an upset stomach, they should be taken with food, not on an empty stomach [53, 54].

In the absence of pulse oximetry, if the patient appears cyanosed and/or distressed, oxygen should be given through nasal cannulae or using a face mask. Observe the patient closely for deterioration, drowsiness or fatigue $[15,27,43,44]$. If oximetry is available and oxygen saturations are below $94 \%$, supplemental oxygen should be given to maintain saturations of $93-95 \%[15,43]$, with a maximum of 98\% [27]. Excessive oxygenation can be harmful and may increase the risk of hypercapnia $[15,27,43,55]$. Where supplemental oxygen is not available, monitor the patient very closely, transferring as soon as possible to an acute care facility.

Reassess all patients after $1 \mathrm{~h}$ (sometimes sooner) [15]. If the response to initial SABA is suboptimal give further doses as needed (4-10 puffs every $3-4 \mathrm{~h}$ or even every $1-2 \mathrm{~h}$ if the clinical situation demands it) [15]. If symptoms fully resolve, consider sending the patient home with an asthma management plan, preventative and relief therapy together with a follow-up appointment date. Should symptoms fail to improve, or if the response to initial SABA administration is poor [56], start treatment as for a severe attack as described in the next section and arrange urgent transfer to an acute care setting [15]. Close observation is essential [44].

\section{Severe or Life-Threatening Asthma Attacks}

These patients need urgent transfer to an acute care facility preferably by ambulance [15]. Drowsiness, confusion, collapse, cyanosis, a silent chest, altered consciousness or oxygen saturations below 90\% represent potentially life-threatening situations [15, 43]. Whilst awaiting transfer, patients should remain under the direct supervision of a healthcare professional within the primary care facility and be continuously monitored for signs of hypoxaemia, worsening conscious levels, fatigue and/ or somnolence $[15,43]$. Give salbutamol up to 10 puffs via a pMDI plus spacer every 20 min up to $1 \mathrm{~h}$ then up to 10 puffs every $1-2$ or $3-4 \mathrm{~h}$. Consider adding ipratropium bromide 8 puffs (every $20 \mathrm{~min}$ in the first hour and every 4-6 h subsequently) $[15,43,44]$. Patients with moderate to severe asthma attacks who were receiving both salbutamol and ipratropium bromide were at lower risk of needing hospital admission than those on salbutamol alone [57]. They did, however. experience more side effects. Give OCS as described in the previous section, and continue supplemental oxygen and SABA until transport arrives [27].

The aforementioned guidance is summarised in the algorithm for the treatment of acute attacks (Fig. 3).

\section{Antibiotic Therapy}

The use of antibiotics in the management of acute asthma is not recommended, unless there is strong evidence of a bacterial infection $[15,58]$. Most infections initiating an attack are likely to be viral in origin [27]. 


\section{Device Choice for Managing Attacks}

A nebuliser and pMDI plus large volume spacer are both options for SABA treatment $[15,27]$. Spacers reduce the requirement for patients to coordinate actuation and inhalation, thereby improving delivery of medicines into the airways where they are needed [59]. During acute attacks a pMDI and spacer is the preferred route of SABA delivery, and the most cost-effective $[15,60]$. While nebulisers are generally not recommended especially for inhaled steroids and in the current pandemic situation [12-14], they may be helpful in those who have lifethreatening asthma or who are agitated, distressed or finding difficulty in using a pMDI and spacer [44], and should be administered with appropriate care $[61,62]$.

\section{CONTINUITY OF CARE}

The advice on patient continuity of care following an asthma attack remains unchanged [12] with requirement for a clear follow-up and review pathway in place, as described in the next section. Patients with asthma should be advised to look out for any worsening symptoms with clear advice on what to do and, with the potential for long waits for remote assessment, patients should be advised to have a low threshold to call the emergency services, in cases where symptoms deteriorate [35].

\section{Follow-Up Appointment}

A follow-up appointment in primary care, whether face to face or by remote monitoring, is an important next step for preventing future asthma attacks, both for attacks managed fully in primary care and those managed in acute care settings (Fig. 4) [15]. Following discharge from an acute care facility, a significant proportion of patients with asthma relapse within 4 weeks [63], highlighting the importance of an early follow-up in primary care to ensure that adequate, regular preventative therapy has been prescribed and is being taken. Depending on the asthma severity and the patient's social circumstances, all patients should have a primary care follow-up appointment soon after an attack, preferably within 2-7 days but certainly within 2 weeks $[15,27]$.

At follow-up, it is important to establish the risk factors that led to the attack and the risk factors for further asthma attacks [15, 27]. Comorbidities such as rhinitis are common and need managing $[15,64,65]$. Discussions should check that resources at home are adequate, including access to medications/spacer device, medication affordability and parent/carer awareness [15, 31, 65]. In low- and middle-income countries, patient affordability is a key consideration that influences treatment choice [65]. Inhaler technique and the patient's asthma action plan should also be reviewed $[15,27]$. Subsequent reviews should be scheduled to assess the effectiveness of medication, and when asthma is well controlled, the frequency of reviews can be reduced [15]. These reviews could be either face to face or via social media platforms, the latter as used during the COVID-19 pandemic.

Overcoming the barriers to managing acute asthma attacks in primary care is essential to effectively treat existing symptoms, achieve long-term asthma control and help prevent future episodes. Every follow-up encounter should be viewed as an opportunity to review and extend patient knowledge and confidence with asthma management [27]. In addition to optimised controller medication, provision of patient education and an asthma action plan are integral components of effective follow-up [66].

Figure 5 provides an overview of the potential barriers to the management of acute attacks of asthma in primary care and summarises associated mitigating actions.

\section{Prevention of Future Asthma Attacks}

\section{Inhaler Technique}

Many patients with asthma are unable to use their inhaler correctly $[67,68]$. Common errors in the use of inhalers include exhalation during actuation, lack of hand-breath coordination, breath-hold too short, inspiratory flow too 


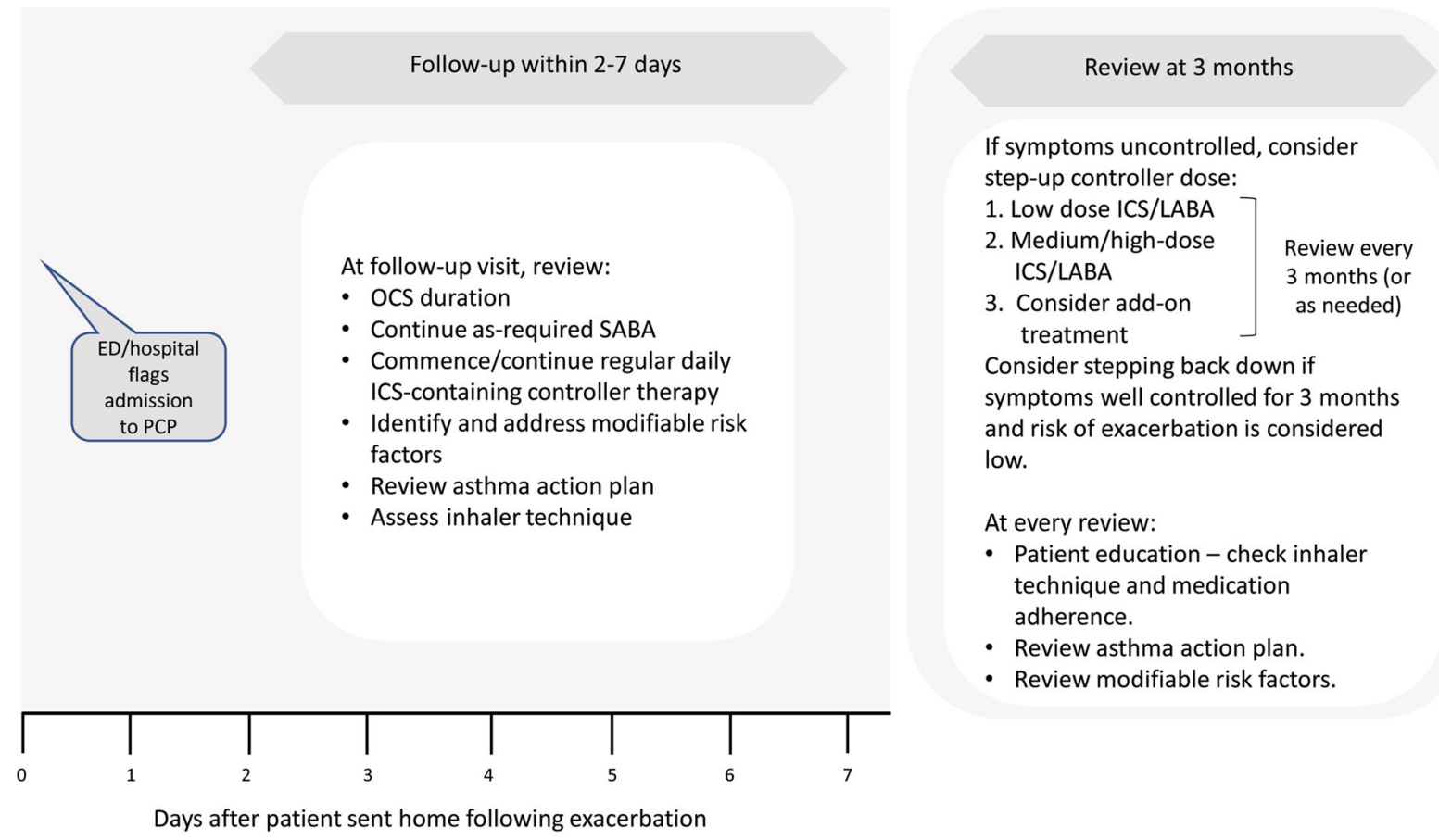

Fig. 4 Primary care follow-up after an acute attack of asthma [15]. ED emergency department, GP general practitioner, ICS inhaled corticosteroid, $L A B A$ long-acting $\beta_{2}$-agonist, $O C S$ oral corticosteroid, $S A B A$ short-acting $\beta_{2}$-agonist

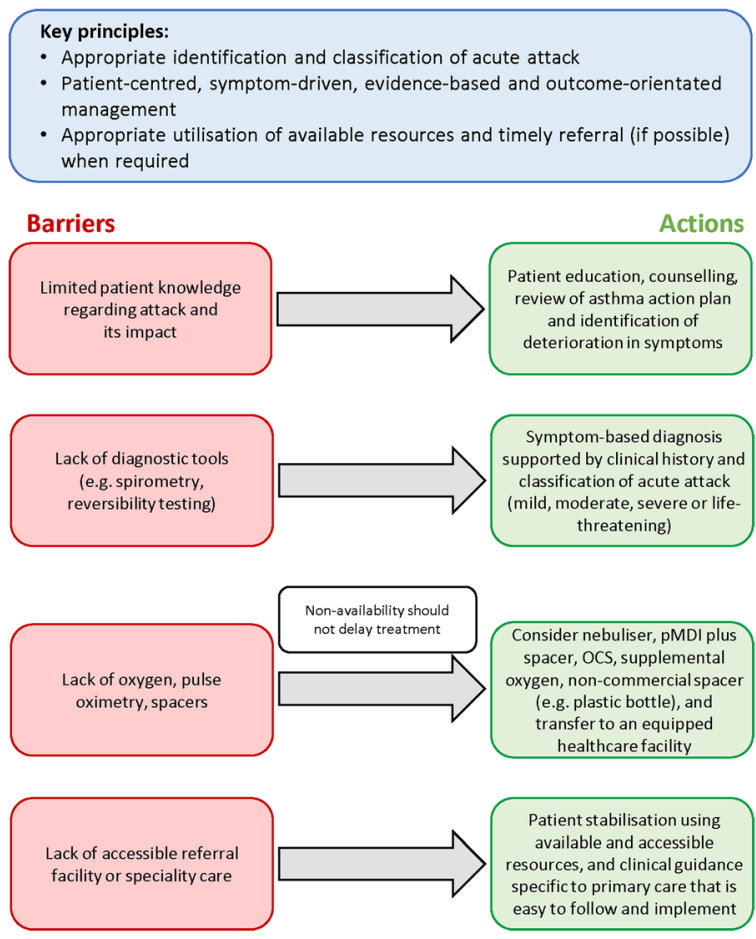

Fig. 5 Overcoming barriers to the management of acute asthma in primary care. OCS oral corticosteroid, $p M D I$ pressurised metered-dose inhaler rapid, and inadequate shaking of inhaler [67]. It is a good idea to check a patient's inhaler technique regularly, particularly following an asthma attack, and to determine causes of poor technique. Assessing inhaler technique remotely is challenging but can and should be done $[45,46]$.

A review of inhaler technique critical errors indicated that $50 \%$ of patients with asthma fail to maintain correct inhaler technique over time and highlighted the importance of patient psychosocial factors for maintaining good inhaler skills [69]. In a qualitative, questionnaire-based study, Jahedi et al. reported that patients intrinsically linked inhalation device use, selection, and preference to medication effectiveness, overall views about asthma management, and belief and trust that their healthcare providers could make decisions about their medications for them [68]. Therefore, emphasizing that the correct inhalation technique can lead to better asthma control and fewer side effects may provide motivation for patients to learn and maintain a good inhaler technique [68]. 
Referral to an appropriately trained asthma nurse or pharmacist for education can be helpful [15]. Some patients may also benefit from the use of approved and reputable web-based inhaler training videos to supplement this [70].

\section{Medications to Control Asthma}

All patients who have had an asthma attack should be prescribed regular daily ICS-containing controller therapy [15], which should be started early to avoid the risk of repeated attacks [71]. Proactive regular dosing with ICS-containing therapies achieves symptom control and reduces attacks [15, 72], both of which should be targeted for effective management of asthma $[15,27,43]$. In patients who are adherent and using their inhalers correctly, if symptoms remain uncontrolled after an attack, and/ or the patient is at high risk of a future attack, treatment may be stepped up to a fixed-dose combination of ICS with a long-acting beta-agonist (LABA), plus 'as-required' use of SABA as a reliever [15]. Regular daily dosing with combined ICS and LABA is most effective in preventing severe attacks of asthma compared with other controller therapies, including ICS alone $[73,74]$. The AUSTRI study, a large randomised controlled trial of patients with a history of asthma attacks $(N=11,751)$, demonstrated a $21 \%$ reduced risk of a severe attack with fluticasone propionate combined with salmeterol compared with fluticasone propionate alone [74].

In patients receiving regular maintenance therapy with either ICS or ICS-LABA plus SABA as a reliever, patterns of increased SABA use can serve as an indicator of an impending attack and should be heeded as a marker of uncontrolled asthma [75, 76]. This should prompt patient evaluation by the physician and, if appropriate, changes to their treatment including close follow-up and reinforcing the use of an asthma action plan. In a database cohort study analysis, Nwaru et al. reported that, despite the increased risks associated with long-term high SABA use, these patterns of SABA use did not trigger any increases in maintenance ICS therapy, highlighting the need for paying closer attention to these patients to establish asthma control [76].

\section{Adherence to Treatment}

Many patients with asthma fail to take their medicines at least some of the time [77], with mean levels of adherence reported as ranging between 22\% and 70\% [78-83]. Factors contributing to poor adherence include a perceived burdensome medication regimen, cost, forgetfulness, poor health literacy, side effects, cultural issues or psychosocial factors [77, 84]. Poor adherence to controller treatment is a risk factor for poor asthma outcomes including increased risk of asthma attacks [85-87]. A simple message for patients is that taking their regular controller medications as recommended is a good way to avoid attacks.

A lack of adherence may be intentional or non-intentional and establishing the rationale of non-adherence will help to find solutions to improve it [81]. Methods to encourage better adherence include simplifying treatment regimes, reducing the frequency of dosing, providing advice on medication reminders, and including patients in treatment decisions [15]. An understanding of a patient's perceptions about their asthma may also help to identify and address their reasons for poor adherence [80]. The use of smart devices, where available, may also provide a useful tool for assessing adherence remotely $[45,46]$.

\section{Asthma Action Plan}

Patient-led written asthma action plans have been recommended for many years [15, 50], with the aim of reducing the likelihood of future attacks and of dying from asthma. They have been shown to improve health outcomes including fewer emergency department visits and hospitalisations [50]. An effective asthma action plan advises patients what to do in the event of worsening asthma symptoms, how to make short-term adjustments to their regular medications to manage their condition and provides clear instructions on how and when to access medical care $[15,88]$. Primary care physicians should bear in mind the available healthcare resources, patient literacy levels and cultural factors [15]. Figure S1 (Supplementary Material) provides an effective example of an asthma action plan, which has been developed by Asthma UK [88]. 


\section{Patient Training and Education}

Patient education forms the basis for encouraging good adherence and effective self-management of asthma [80]. Patient understanding of the purpose of adherence to medication, follow-up appointments and correct inhaler technique should be reviewed and its importance reiterated $[15,43]$. The value of educational interventions has been demonstrated in terms of both improved adherence and asthma outcomes [80]. Asthma attacks can represent a failure in management due to poor health literacy [43]; therefore, educational materials should be formatted and tailored to the needs of individual patients [80].

Patient education should also include a patient-centred discussion around minimising environmental attack triggers, cigarette smoke and avoidance of allergens [27, 89, 90].

\section{WHAT HAS BEEN THE IMPACT OF COVID-19 ON ASTHMA ATTACKS AND WHAT ARE THE LEARNINGS FROM COVID-19?}

During the COVID-19 pandemic, significant reductions in severe asthma attacks have been reported, in both primary care [3] and in those needing hospital admission $[5,6]$. The reasons for this are not totally understood but could be multifactorial and may include a decrease in air pollution, due to the reduction in the use of cars, a decrease in the circulation of respiratory viruses associated with distancing measures and wearing of masks, and improved self-management including increased adherence to preventative medications $[8,9,14]$. Understanding the reasons for such reductions could provide future learnings for managing patients with asthma [8]. Chalitsios et al. reported an increase in ICS prescriptions at the outbreak of the pandemic in the UK, with a decrease to baseline levels over the following months [91]. Analysis of digitally collected adherence data, based on electronic monitoring, demonstrated a $14.5 \%$ increase in adherence to controller medications during the first few months of the pandemic [9]. This suggests an increased recognition of asthma as a comorbidity and a heightened awareness of the importance of the disease. Understanding patients' perceptions and concerns during this period could provide an opportunity to improve patient self-management and reduce avoidable attacks [8].

Several recent publications have highlighted that asthma outcomes, including mortality, are not worsened by COVID-19 infection, even suggesting some protective effects. In a systematic literature review of 62 studies, Hou et al. reported that asthma was associated with a reduced risk of COVID-19 mortality [11]. The mechanism for this is unclear but the authors suggested that it could be related to an increase in medical care received by patients with asthma and COVID-19 infection, or due to an anti-inflammatory protective effect associated with the type 2 immune response in patients with asthma or possibly from their treatment with ICS. Lombardi et al. also suggested that downregulation of angiotensin-converting enzyme 2 (ACE2) receptors, as well as chronic type 2 inflammation, younger age, absence of comorbidities and reduced viral exposure due to shielding in patients with asthma might be possible mechanisms by which asthma protects against COVID-19 infection and poor outcomes [2]. Another review and meta-analysis of 57 studies reported that patients with asthma have a lower risk of acquiring COVID-19, a possible explanation being the downregulation of ACE2 receptors observed in type 2-high asthma and with ICS treatment [92]. Asthmatics with confirmed COVID-19 based on positive reverse transcriptase-polymerase chain reaction (rtPCR) test, however, have been reported to have a similar risk of hospitalisation, ICU admission, ventilator use and mortality as those without asthma [93]. Thus, maintaining asthma control with appropriate asthma maintenance therapy remains vital to avoid any deterioration and subsequent need for urgent healthcare visits.

\section{CONCLUSIONS}

The pandemic was an opportunity to increase the awareness of asthma as a chronic condition and the importance of managing asthma 
attacks. Well-managed asthma does not appear to worsen COVID-related outcomes, despite early concerns and may even offer some protection against COVID-related detrimental effects. Acute attacks of asthma can be well managed and, more importantly, prevented in primary care. During pandemics caused by respiratory viruses, such as in COVID-19, it is even more important for patients and PCPs to recognise asthma attacks and instigate early intervention, whether face to face or remotely. Remote assessment is more challenging but can be achieved with structural clinical assessment and the use of home monitoring devices where appropriate and available. The advice and algorithms provided in this article aim to simplify the appropriate and timely diagnosis, classification and treatment of acute attacks in adults and in teenagers. Continuity of care following an attack is crucial to establish its main cause and to agree the best preventative therapy that can help reduce further attacks. Proactive regular dosing with ICS-containing therapies achieves symptom control and reduces attacks, both of which should be targeted for effective management of asthma.

\section{ACKNOWLEDGEMENTS}

Funding. Funding for this article was provided by GSK. GSK funded the journal's Rapid Service and Open Access fees.

Medical Writing Assistance. Medical writing assistance (in the form of assistance with developing the initial draft of the manuscript, collating author comments, copyediting and compiling figures and tables) was provided by Gillian Wallace, MSc, at Fishawack Indicia Ltd, UK, and Kate Hollingworth of Continuous Improvement Ltd, UK, and was funded by GlaxoSmithKline (GSK).

Authorship. All named authors meet the International Committee of Medical Journal Editors (ICMJE) criteria for authorship for this article, take responsibility for the integrity of the work as a whole, and have given their approval for this version to be published.

Author Contributions. All authors were involved in the conception/design of this manuscript, the acquisition of data, and data interpretation. All authors approved the final version prior to submission.

Disclosures. Monica Fletcher is a former employee of GSK. Warren Lenney is a former employee of GSK and holds GSK stocks/shares. Thys van der Molen is a former GSK employee and has provided advisory board consultancy for Chiesi. Bhumika Aggarwal, Isabelle Boucot and Emilio Pizzichini are employees of, and hold stocks/shares in, GSK.

Compliance with Ethics Guidelines. This article is based on previously conducted studies and does not contain any studies with human participants or animals performed by any of the authors.

Data Availability. Data sharing is not applicable to this article as no datasets were generated or analyzed during the current study.

Open Access. This article is licensed under a Creative Commons Attribution-NonCommercial 4.0 International License, which permits any non-commercial use, sharing, adaptation, distribution and reproduction in any medium or format, as long as you give appropriate credit to the original author(s) and the source, provide a link to the Creative Commons licence, and indicate if changes were made. The images or other third party material in this article are included in the article's Creative Commons licence, unless indicated otherwise in a credit line to the material. If material is not included in the article's Creative Commons licence and your intended use is not permitted by statutory regulation or exceeds the permitted use, you will need to obtain permission directly from the copyright holder. To view a copy of this licence, visit http://creativecommons.org/licenses/by$\mathrm{nc} / 4.0 /$. 


\section{REFERENCES}

1. Jordan RE, Adab P, Cheng KK. Covid-19: risk factors for severe disease and death. BMJ. 2020;368:m1198.

2. Lombardi C, Gani F, Berti A, Comberiati P, Peroni D, Cottini M. Asthma and COVID-19: a dangerous liaison? Asthma Res Pract. 2021;7(1):9.

3. Shah SA, Quint JK, Nwaru BI, Sheikh A. Impact of COVID-19 national lockdown on asthma exacerbations: interrupted time-series analysis of English primary care data. Thorax. 2021;76:860-6.

4. de Boer G, Braunstahl G, Hendriks R, et al. Asthma exacerbation prevalence during the COVID-19 lockdown in a moderate-severe asthma cohort. BMJ Open Respir Res. 2021;8:e00758.

5. Davies GA, Alsallakh MA, Sivakumaran S, et al. Impact of COVID-19 lockdown on emergency asthma admissions and deaths: national interrupted time series analyses for Scotland and Wales. Thorax. 2021;76:867-73.

6. Huh K, Kim Y, Ji W, et al. Decrease in hospital admissions for respiratory diseases during the COVID-19 pandemic: a nationwide claims study. Thorax. 2021;76:939-41.

7. Salciccioli JD, She L, Tulchinsky A, Rockhold F, Cardet JC, Israel E. Effect of COVID-19 on asthma exacerbation. J Allergy Clin Immunol Pract. 2021;9(7):2896-2899.e1.

8. Skene IP, Pfeffer PE. Improved asthma control during the COVID-19 pandemic: are there lessons to be learnt? Thorax. 2021;76:852-3.

9. Kaye L, Theye B, Smeenk I, Gondalia R, Barrett MA, Stempel DA. Changes in medication adherence among patients with asthma and COPD during the COVID-19 pandemic. J Allergy Clin Immunol Pract. 2020;8:2384-5.

10. Wu X, Xu Y, Jin L, Wang X, Zhu H, Xie Y. Association of preexisting asthma and other allergic diseases with mortality in COVID-19 patients: a systematic review and meta-analysis. Front Med (Lausanne). 2021;8:670744.

11. Hou H, Xu J, Li Y, Wang Y, Yang H. The association of asthma with COVID-19 mortality: an updated meta-analysis based on adjusted effect estimates. J Allergy Clin Immunol Pract. 2021;9(11):39443968.e5.

12. Primary Care Respiratory Society UK. PCRS Pragmatic Guidance. Diagnosing and managing asthma attacks and people with COPD presenting in crisis during the UK Covid 19 epidemic. 2020. https:// www.pcrs-uk.org/sites/pcrs-uk.org/files/resources/ COVID19/PCRS-Covid-19-Pragmatic-Guidance-v407-May-2020.pdf. Accessed 2 July 2021.

13. British Thoracic Society Advice for healthcare professionals treating people with asthma (adults) in relation to COVID-19. 2020. https://www.britthoracic.org.uk/document-library/qualityimprovement/covid-19/bts-advice-for-healthcareprofessionals-treating-patients-with-asthma/. Accessed 2 July 2021.

14. Global Initiative for Asthma (GINA). GINA guidance about COVID-19 and asthma. https:// ginasthma.org/wp-content/uploads/2021/03/21_ 03_30-GINA-COVID-19-and-asthma.pdf. Accessed 2 July 2021.

15. Global Initiative for Asthma (GINA). Global Strategy for Asthma Management and Prevention. 2021. https://ginasthma.org/gina-reports/. Accessed 2 July 2021.

16. Pavord ID, Beasley R, Agusti A, et al. After asthma: redefining airways diseases. Lancet. 2018;391(10118):350-400.

17. Jones KA, Gibson PG, Yorke J, Niven R, Smith A, McDonald VM. Attack, flare-up, or exacerbation? The terminology preferences of patients with severe asthma. J Asthma. 2021;58(2):141-50.

18. Suruki RY, Daugherty JB, Boudiaf N, Albers FC. The frequency of asthma exacerbations and healthcare utilization in patients with asthma from the UK and USA. BMC Pulm Med. 2017;17:74.

19. Dennis RJ, Solarte I, Rodrigo G. Asthma in adults. BMJ Clin Evid. 2011;2011:1501.

20. Blakey JD, Woolnough K, Fellows J, Walker S, Thomas M, Pavord ID. Assessing the risk of attack in the management of asthma: a review and proposal for revision of the current control-centred paradigm. Prim Care Respir J. 2013;22:344-52.

21. Dusser D, Montani D, Chanez P, et al. Mild asthma: an expert review on epidemiology, clinical characteristics and treatment recommendations. Allergy. 2007;62:591-604.

22. Blakey JD, Price DB, Pizzichini E, et al. Identifying risk of future asthma attacks using UK medical record data: a respiratory effectiveness group initiative. J Allergy Clin Immunol Pract. 2017;5: 1015-24.

23. Price D, Wilson AM, Chisholm A, et al. Predicting frequent asthma exacerbations using blood eosinophil count and other patient data routinely available in clinical practice. J Asthma Allergy. 2016;9:1-12. 
24. Miller MK, Lee JH, Miller DP, Wenzel SE, TENOR Study Group. Recent asthma exacerbations: a key predictor of future exacerbations. Respir Med. 2007; 101:481-9.

25. Bloom CI, Nissen F, Douglas IJ, Smeeth L, Cullinan P, Quint JK. Exacerbation risk and characterisation of the UK's asthma population from infants to old age. Thorax. 2018;73:313-20.

26. Busse WW, Bateman ED, Caplan AL, et al. Combined analysis of asthma safety trials of long-acting ß2-agonists. N Engl J Med. 2018;378:2497-505.

27. The British Thoracic Society. BTS/SIGN British guideline on the management of asthma. 2019. https://www.brit-thoracic.org.uk/standards-of-care/ guidelines/btssign-british-guideline-on-themanagement-of-asthma/. Accessed 2 July 2021.

28. Small I. The majority of asthma cases can be managed in primary care. 2012. https://www. guidelinesinpractice.co.uk/respiratory/themajority-of-asthma-cases-can-be-managed-inprimary-care/335790.article. Accessed 16 Sept 2021.

29. Chung L, Johnson P, Summers Q. Models of care for severe asthma: the role of primary care. Med J Aust. 2018;209:S34-40.

30. Szefler SJ, Fitzgerald DA, Adachi Y, et al. A worldwide charter for all children with asthma. Pediatr Pulmonol. 2020;55:1282-92.

31. Sánchez-Borges M, Capriles-Hulett A, CaballeroFonseca F. Asthma care in resource-poor settings. World Allergy Organ J. 2011;4:68-72.

32. Gibbons DC, Aggarwal B, Fairburn-Beech J, et al. Treatment patterns among non-active users of maintenance asthma medication in the United Kingdom: a retrospective cohort study in the clinical practice research Datalink. J Asthma. 2021;58: 793-804.

33. D'Amato G, Vitale C, Molino A, et al. Asthma-related deaths. Multidiscip Respir Med. 2016;11:37.

34. Royal College of Physicians. Why asthma kills. The national review of asthma deaths (NRAD). 2014. https://www.rcplondon.ac.uk/projects/outputs/ why-asthma-still-kills. Accessed 2 July 2021.

35. Beaney T, Salman D, Samee T, Mak V. Assessment and management of adults with asthma during the COVID-19 pandemic. BMJ. 2020;369:m2092.

36. The Primary Care Respiratory Society (PCRS). PCRS Position Statement. Diagnostic work up of the patient presenting with respiratory symptoms during the COVID-19 pandemic. 2020. https://www. pcrs-uk.org/resource/diagnostic-work-patient- presenting-respiratory-symptoms-during-covid-19pandemic. Accessed 4 Jan 2022.

37. Ramsahai JM, Hansbro PM, Wark PAB. Mechanisms and management of asthma exacerbations. Am J Respir Crit Care Med. 2019;199:423-32.

38. Castillo JR, Peters SP, Busse WW. Asthma exacerbations: pathogenesis, prevention, and treatment. J Allergy Clin Immunol Pract. 2017;5:918-27.

39. Martin MJ, Beasley R, Harrison TW. Towards a personalised treatment approach for asthma attacks. Thorax. 2020;75:1119-29.

40. Tattersfield AE, Postma DS, Barnes PJ, et al. Exacerbations of asthma: a descriptive study of 425 severe exacerbations. The FACET International Study Group. Am J Respir Crit Care Med. 1999;160: 594-9.

41. Bateman ED, O'Byrne PM, Busse WW, et al. Oncedaily fluticasone furoate $(\mathrm{FF}) /$ vilanterol reduces risk of severe exacerbations in asthma versus FF alone. Thorax. 2014;69:312-9.

42. Reddel HK, Busse W, Rabe KF, et al. Heterogeneity and time course of asthma exacerbations: data from AUSTRI. Eur Respir J. 2021;58:PA3716. https://doi. org/10.1183/13993003.congress-2021.PA3716.

43. National Asthma Council Australia. Australia's National Guidelines for Asthma Management. 2020. http://www.asthmahandbook.org.au/ management/adults. Accessed 2 July 2021.

44. National Heart, Lung, and Blood Institute. National Asthma Education and Prevention Program. Expert Panel Report 3: guidelines for the diagnosis and management of asthma. 2007. https://www.nhlbi. nih.gov/sites/default/files/media/docs/asthgdln_1. pdf. Accessed 2 July 2021.

45. Asthma UK. Smart asthma: Real-world implementation of connected devices in the UK to reduce asthma attacks. https://www.asthma.org.uk/ support-us/campaigns/publications/smartasthma/. Accessed 7 Jan 2022.

46. GSK. How can we assess and improve inhaler technique virtually? https://offyourchest.gsk.com/ detail/inhalertechnique. Accessed 7 Jan 2022.

47. Greenhalgh T, Koh GCH, Car J. COVID-19: a remote assessment in primary care. BMJ. 2020;368: 1182.

48. Bakakos A, Krompa A. Asthma in the era of SARS CoV-2 virus. J Asthma. 2021. https://doi.org/10. 1080/02770903.2021.1941093. 
49. Amirav I, Newhouse MT. Asthma and COVID-19: In defense of evidence-based SABA. J Asthma Allergy. 2020;13:505-8.

50. Gibson PG. Written action plans for asthma: an evidence-based review of the key components. Thorax. 2004;59:94-9.

51. Kew KM, Quinn M, Quon BS, Ducharme FM. Increased versus stable doses of inhaled corticosteroids for exacerbations of chronic asthma in adults and children. Cochrane Database Syst Rev. 2016;6:CD007524.

52. Harrison TW, Oborne J, Newton S, Tattersfield AE. Doubling the dose of inhaled corticosteroid to prevent asthma exacerbations: randomised controlled trial. Lancet. 2004;363(9405):271-5.

53. Asthma UK. Steroids: Asthma steroids help to calm and prevent inflammation in the airways to keep symptoms under control. 2016. https://www. asthma.org.uk/advice/inhalers-medicinestreatments/steroids/. Accessed 16 Sept 2021.

54. Richards R. Side-effects of short-term oral corticosteroids. J Cutan Med Surg. 2018;12:77-81.

55. Perrin K, Wijesinghe M, Healy B, et al. Randomised controlled trial of high concentration versus titrated oxygen therapy in severe exacerbations of asthma. Thorax. 2011;66:937-41.

56. Fergeson JE, Patel SS, Lockey RF. Acute asthma, prognosis, and treatment. J Allergy Clin Immunol. 2017;139:438-47.

57. Kirkland SW, Vandenberghe C, Voaklander B, Nikel T, Campbell S, Rowe BH. Combined inhaled betaagonist and anticholinergic agents for emergency management in adults with asthma. Cochrane Database Syst Rev. 2017;1:CD001284.

58. Normansell R, Sayer B, Waterson S, Dennett EJ, Del Forno M, Dunleavy A. Antibiotics for exacerbations of asthma. Cochrane Database Syst Rev. 2018;6: CD002741.

59. Anderson G, Johnson N, Mulgirigama A, Aggarwal B. Use of spacers for patients treated with pressurized metered dose inhalers: focus on the VENTOLIN $^{\mathrm{TM}}$ Mini Spacer. Expert Opin Drug Deliv. 2018;15:419-30.

60. Newman B, Milne S, Hamilston C, Hall KA. Comparison of albuterol administered by metered-dose inhaler and spacer with albuterol by nebulizer in adults presenting to an urban emergency department with acute asthma. Chest. 2002;121:1036-41.
61. Ari A. Practical strategies for a safe and effective delivery of aerosolized medications to patients with COVID-19. Respir Med. 2020;167:105987.

62. Levin M, Ansotegui IJ, Bernstein J, et al. Acute asthma management during SARS-CoV2-pandemic 2020. World Allergy Organ J. 2020;13(5):100125.

63. Hill J, Arrotta N, Villa-Roel C, Dennett L, Rowe BH. Factors associated with relapse in adult patients discharged from the emergency department following acute asthma: a systematic review. BMJ Open Resp Res. 2017;4:e000169.

64. Boulet LP. Influence of comorbid conditions on asthma. Eur Respir J. 2009;33:897-906.

65. Aggarwal B, Shantakumar S, Hinds D, Mulgirigama A. Asia-Pacific Survey of Physicians on Asthma and Allergic Rhinitis (ASPAIR): physician beliefs and practices about diagnosis, assessment, and treatment of coexistent disease. J Asthma Allergy. 2018;11:293-307.

66. FitzGerald JM, Gibson PG. Asthma exacerbations. 4: prevention. Thorax. 2006;61:992-9.

67. Price DB, Román-Rodríguez M, McQueen RB, et al. Inhaler errors in the CRITIKAL study: type, frequency, and association with asthma outcomes. J Allergy Clin Immunol Pract. 2017;5:1071-1081.e9.

68. Jahedi L, Downie SR, Saini B, Chan HK, BosnicAnticevich S. Inhaler technique in asthma: how does it relate to patients' preferences and attitudes toward their inhalers? J Aerosol Med Pulm Drug Deliv. 2017;30:42-52.

69. Bosnic-Anticevich SZ, Cvetkovski B, Azzi EA. Identifying critical errors: addressing inhaler technique in the context of asthma management. Pulm Ther. 2018;4:1-12.

70. Müller T, Müller A, Hübel C, et al. Optimizing inhalation technique using web-based videos in obstructive lung diseases. Respir Med. 2017;129: $140-4$.

71. Stanford RH, Buikema AR, Riedel AA, Camargo CA Jr, Rey GG, Chapman KR. Asthma controller delay and recurrence risk after an emergency department visit or hospitalization. Respir Med. 2012;106: 1631-8.

72. Bateman ED, Boushey HA, Bousquet J, et al. Can guideline-defined asthma control be achieved? The Gaining Optimal Asthma Control study. Am J Respir Crit Care Med. 2004;170:836-44.

73. Loymans RJB, Gemperli A, Cohen J, et al. Comparative effectiveness of long term drug treatment 
strategies to prevent asthma exacerbations: network meta-analysis. BMJ. 2014;348:g3009.

74. Stempel DA, Raphiou IH, Kral KM, et al. Serious asthma events with fluticasone plus salmeterol versus fluticasone alone. N Engl J Med. 2016;374: 1822-30.

75. Stanford RH, Shah MB, D'Souza AO, Dhamane AD, Schatz M. Short-acting-agonist use and its ability to predict future asthma-related outcomes. Ann Allergy Asthma Immunol. 2012;109:403-7.

76. Nwaru BI, Ekström M, Hasvold P, Wiklund F, Telg $\mathrm{G}$, Janson C. Overuse of short-acting $\beta 2$-agonists in asthma is associated with increased risk of exacerbation and mortality: a nationwide cohort study of the global SABINA programme. Eur Respir J. 2020;55:1901872.

77. Boulet LP, Vervloet D, Magar Y, Foster JM. Adherence: the goal to control asthma. Clin Chest Med. 2012;33:405-17.

78. Cerveri I, Locatelli F, Zoia MC, Corsico A, Accordini $\mathrm{S}$, de Marco R. International variations in asthma treatment compliance: the results of the European Community Respiratory Health Survey (ECRHS). Eur Respir J. 1999;14:288-94.

79. Bender B, Wamboldt FS, O'Connor SL, et al. Measurement of children's asthma medication adherence by self report, mother report, canister weight, and Doser CT. Ann Allergy Asthma Immunol. 2000;85:416-21.

80. Eakin MN, Rand CS. Improving patient adherence with asthma self-management practices: what works? Ann Allergy Asthma Immunol. 2012;109: 90-2.

81. Mäkelä MJ, Backer V, Hedegaard M, Larsson K. Adherence to inhaled therapies, health outcomes and costs in patients with asthma and COPD. Respir Med. 2013;107:1481-90.

82. Price D, Fletcher M, van der Molen T. Asthma control and management in 8000 European patients: the REcognise Asthma and LInk to Symptoms and Experience (REALISE) survey. NPJ Prim Care Respir Med. 2014;24:14009.

83. Bårnes $\mathrm{CB}$, Ulrik CS. Asthma and adherence to inhaled corticosteroids: current status and future perspectives. Respir Care. 2015;60:455-68.

84. Foster JM, Aucott L, van der Werf RH, et al. Higher patient perceived side effects related to higher daily doses of inhaled corticosteroids in the community: a cross-sectional analysis. Respir Med. 2006;100: 1318-36.

85. Engelkes M, Janssens HM, de Jongste JC, Sturkenboom MC, Verhamme KM. Medication adherence and the risk of severe asthma exacerbations: a systematic review. Eur Respir J. 2015;45:396-407.

86. Killane I, Sulaiman I, MacHale E, et al. Predicting asthma exacerbations employing remotely monitored adherence. Healthc Technol Lett. 2016;3: $51-5$.

87. Ismaila A, Corriveau D, Vaillancourt J, et al. Impact of adherence to treatment with fluticasone propionate/salmeterol in asthma patients. Curr Med Res Opin. 2014;30:1417-25.

88. Asthma UK. Filling in patient's asthma action plans. 2019 https://www.asthma.org.uk/ globalassets/health-advice/resources/adults/adultasthma-action-plan.pdf. Accessed 16 Sept 2021.

89. Eisner MD, Klein J, Hammond SK, Koren G, Lactao G, Iribarren C. Directly measured second hand smoke exposure and asthma health outcomes. Thorax. 2005;60:814-21.

90. Schatz M, Rachelefsky G, Krishnan JA. Follow-up after acute asthma episodes: what improves future outcomes? Proc Am Thorac Soc. 2009;6:386-93.

91. Chalitsios CV, Tricia MM, Langley TE, Shaw DE. Impact of COVID-19 on corticosteroids and antibiotics prescribing in England: an interrupted time series analysis. J Public Health. 2021. https:// doi.org/10.1093/pubmed/fdab017.

92. Sunjaya AP, Allida SM, Di Tanna GL, Jenkins C. Asthma and risk of infection, hospitalization, ICU admission and mortality from COVID-19: systematic review and meta-analysis. J Asthma. 2021;1: $1-14$.

93. Sunjaya AP, Allida SM, Di Tanna GL, Jenkins CR. Asthma and coronavirus disease 2019 risk: a systematic review and meta-analysis. Eur Respir J. 2021;24:2101209. https://doi.org/10.1183/ 13993003.01209-2021.

94. Asthma UK. Meet your asthma healthcare team. 2019. https://www.asthma.org.uk/advice/nhs-care/ healthcare-team/\#asthmanurses. Accessed $16 \mathrm{Sept}$ 2021. 